\title{
La internacionalización de las universidades valencianas a través de Twitter
}

\section{The internationalization of Valencian universities through Twitter}
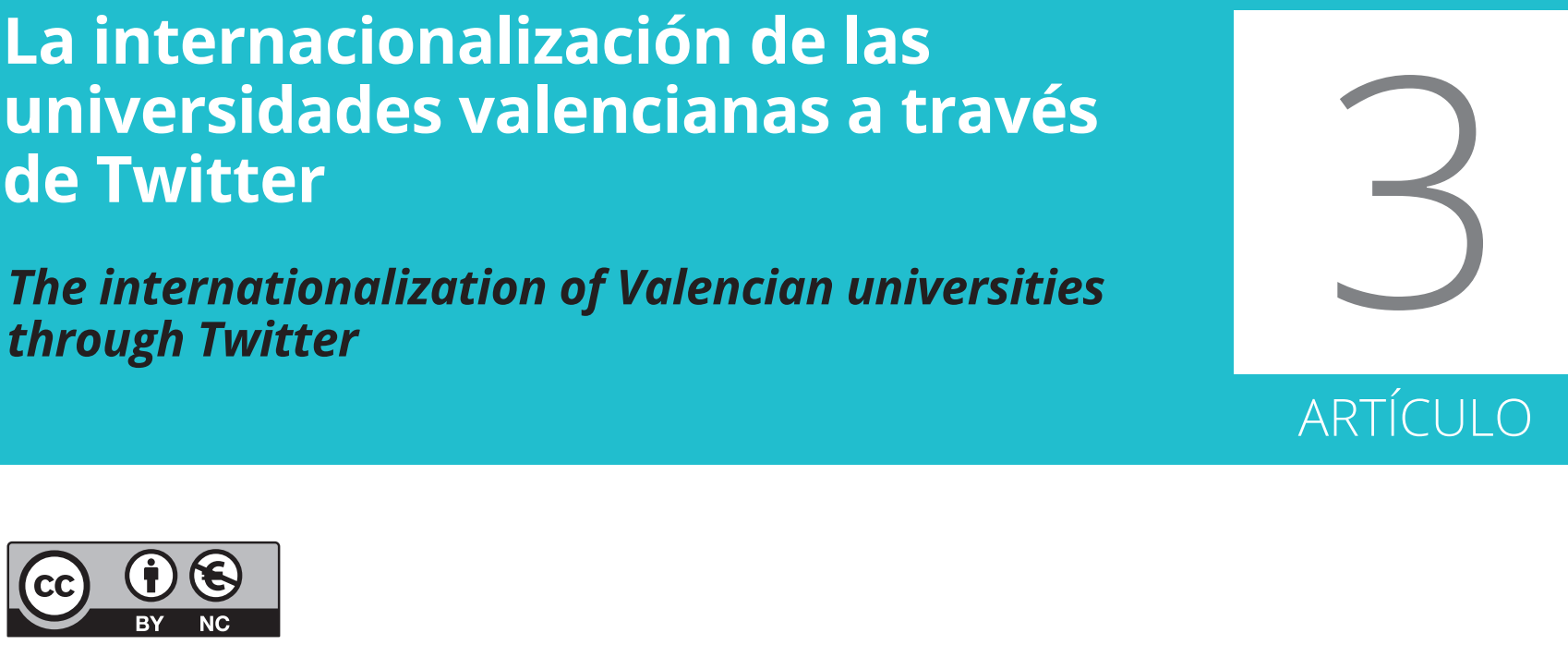

\section{Adolfo Carratalá}

\author{
Departamento de Teoría de los Lenguajes y Ciencias de la Comunicación
}

Licenciado (2007) y doctor en Periodismo (2012, Premio Extraordinario) por la Universitat de València (UV). Actualmente trabaja como Profesor Ayudante Doctor de Periodismo en la Universitat de València, donde imparte las asignaturas Teoría e Historia del Periodismo y Periodismo de Sociedad y Cultura. Su tesis doctoral, en la que analiza la cobertura periodística sobre la controversia en torno a la implantación de la asignatura Educación para la Ciudadanía, obtuvo el Premio Lorenzo Gomis de la Sociedad Española de Periodística en 2013. Sus líneas de investigación actuales se centran en el análisis del tratamiento periodístico de la acción colectiva, la cobertura de conflictos sociales y estudios LGTBI.

adolfo.carratala@uv.es

orcid.org/0000-0002-9865-9246

\section{Etián Menencia García}

Universidad de Matanzas

Departamento de redes de la Dirección de Informatización

Jefe del Departamento de Redes de la Dirección de Informatización de la Dirección General.

etian90@gmail.com

orcid.org/0000-0003-4329-9025

Fecha de recepción: 02 de febrero de 2019 / Aceptación: 05 de junio de 2019 


\section{Resumen}

La internacionalización está cobrando gran importancia en las estrategias de comunicación institucional de las universidades españolas. Las redes sociales se revelan como el mejor canal para construir la marca en busca de estudiantes e investigadores, a fin de aumentar la proyección a nivel internacional. Esta investigación analiza el modo en que las cinco universidades públicas de la Comunitat Valenciana aprovechan la comunicación corporativa a través de Twitter para profundizar en sus políticas de internacionalización. El estudio demuestra que las acciones relacionadas con la innovación y la transferencia de conocimientos dominan la comunicación institucional en Twitter de las instituciones examinadas.

\section{PALABRAS CLAVE}

Internacionalización, comunicación institucional, universidad, TIC, redes sociales, Twitter.

\section{Abstract}

Internationalization policies are becoming very important in the institutional communication strategies of Spanish universities. Social networks are presented as the best channel to build the brands of universities in search of students and researchers to increase their international projection. This research analyzes how the five public universities of the Valencian Community take advantage of corporate communication through Twitter to increase their internationalization policies. The study shows that actions related to knowledge transfer and innovation dominate the institutional communication of the examined universities on Twitter.

\section{KEYWORDS}

Internationalization, institutional communication, university, ICT, social networks, Twitter.

\section{INTRODUCCIÓN}

Las instituciones universitarias están prestando cada vez mayor atención a la gestión de su imagen corporativa, dado que contar con una marca corporativa fuerte es un activo que reporta grandes beneficios a los centros educativos de educación superior al permitir aumentar la competitividad de la institución (Takaki, 2015). Además, la comunicación institucional es una de las herramientas más importantes con las que es preciso contar en el diseño de las políticas de internacionalización universitaria, en el marco de las cuales los mensajes producidos y canalizados por la institución deben estar enfocados desde una perspectiva global, que justifique su realización como parte de una estrategia más amplia de comunicación; siempre acorde a los objetivos, políticas institucionales y valores de las mismas (Reina Estevez, Fernández Castillo \& Noguer Jiménez, 2012).

El Grupo de Trabajo responsable de la redacción de la Estrategia de Internacionalización de las Universidades Españolas 2015-2020, impulsado por el Ministerio de Educación, Cultura y Deporte, indica que el concepto de internacionalización:

va más allá de la mera movilidad de estudiantes y firma de acuerdos internacionales. Se deben considerar aspectos de internacionalización de los currículum formativos, circulación de cerebros, internacionalización de la investigación, titulaciones internacionales conjuntas o múltiples con socios extranjeros, internacionalización en casa, desarrollo de campus 
transnacionales, creación de sistemas internacionales de aseguramiento de la calidad, acreditación y verificación, competición por los mejores alumnos, clasificaciones internacionales (ranking) de universidades, desarrollo de asociaciones de antiguos alumnos ("alumni") internacionales, intercambio de experiencias y buenas prácticas, empleabilidad y emprendimiento. (MECD, 2014: 4)

La internacionalización de la educación superior, que tuvo en el proceso de Bolonia su mayor expresión, es una de las tendencias contemporáneas más importantes, ya que genera ganancias y beneficios a las universidades, promoviendo la diversidad de capacidades necesarias para el desarrollo de los países. En el marco de estas políticas, el objetivo primordial se concentra en la atracción de estudiantes y docentes extranjeros y en la formación de los nacionales en el extranjero (Rama, 2012), un propósito para el que la capacidad de visibilización y comunicación de las universidades es clave.

En las últimas dos décadas, la Universidad ha experimentado una enorme transformación e, indudablemente, las TIC han jugado un papel crucial en este proceso (Sangrà \& González Sanmamed, 2004), pues las estrategias tradicionales de comunicación por sí solas no causan el mismo impacto en las nuevas generaciones como hace algunos años. La entrada de Internet en nuestras sociedades ha provocado una modificación de nuestro entorno, puesto que a raíz del desarrollo de la red se han abierto nuevas posibilidades comunicativas, informativas $y$ también de desarrollo de la educación superior (Baelo \& Cantón, 2010).

La web 2.0 ha supuesto una enorme dinamización en el intercambio y difusión de la infor- mación (González-Díaz, Iglesias-García \& Codina, 2015), una revolución comunicativa que en gran medida se debe a los cambios en materia de informatización que ha sufrido la sociedad y que permite a las organizaciones interactuar con sus públicos, comunicándose a un nivel nuevo, sin limitaciones temporales o espaciales (Reina Estevez, Fernández Castillo \& Noguer Jiménez, 2012).

La irrupción de las redes sociales ha cambiado la forma en que se concibe la comunicación entre los actores de la sociedad. Estas herramientas han evolucionado las vías disponibles para la comunicación, añadiendo nuevos canales y llegando a sustituir algunos protocolos preexistentes, abriendo un nuevo escenario del que la universidad, como institución principal en materia de formación y desarrollo de la sociedad, debe ser consciente para adaptarse a él (Reina Estevez, Fernández Castillo \& Noguer Jiménez, 2012). Con la nueva generación protagonizada por los llamados millenials (Moya Camacho \& Orozco Ramírez, 2017), estamos en presencia de un nuevo tipo de usuario, el prosumer, que se ha convertido en el elemento central del proceso comunicativo al dejar de ser un mero observador (Macías-Alegre, 2016), debido a que las nuevas tecnologías le han dado el poder de compartir, crear, informar y comunicarse, convirtiéndose estas en un elemento esencial en su vida (Gómez, Roses \& Farias, 2012). Por este motivo, las estrategias de comunicación corporativa en el ámbito digital, también las de las universidades, deben estar enfocadas a este tipo de usuario, por lo que no han de limitarse a la generación de contenidos, sino que en paralelo se deben tener en cuenta las opiniones de dichos actores y sus aportes.

El uso de las TIC en su conjunto, además de posicionar y difundir la imagen de las instituciones, juega un importante papel en la internacionalización de los modelos de estudio e 
investigaciones de los centros educativos de nivel superior, siendo una herramienta poderosa para los departamentos de marketing o relaciones internacionales de las universidades, aunque la presencia de estas entidades en los medios sociales debe responder a objetivos que estén alineados con la identidad y el plan estratégico propio de cada institución (García García, 2018).

Las instituciones españolas son un referente de internacionalización a través de los medios digitales, estableciendo entre sus objetivos principales la difusión de la marca Study in Spain, recogida en el Plan de Internacionalización y modernización de las universidades españolas. Junto a ello, la red de instituciones de educación superior también coincide en observar la movilidad de estudiantes, investigadores jóvenes, profesores y personal de administración y servicios como el motor para la internacionalización del Espacio Europeo de Educación Superior (EEES), una tarea en la que desde las instituciones europeas se está trabajando para facilitar e impulsar la llegada de extranjeros pertenecientes a tales colectivos y su posterior movilidad entre los Estados miembros de la Unión (MECD, 2014).

En España, el programa Campus de Excelencia Internacional (CEI), impulsado por el Ministerio de Educación, Cultura y Deportes, fomenta el desarrollo de estrategias de internacionalización en universidades españolas mediante las siguientes acciones (MECD, 2014):

1. Desarrollo de campus transfronterizos.

2. Establecimiento de puentes internacionales con movilidad transnacional de aprendizaje y de conocimiento.

3. Establecimiento en el extranjero de centros de excelencia de clase mundial.
4. Organización en España de eventos internacionales.

5. Participación en proyectos, asociaciones y redes internacionales en educación superior, investigación e innovación.

6. Desarrollo de programas y estrategias institucionales de movilidad internacional de aprendizaje, conocimiento y empleo.

Este mismo plan ministerial señala que como prácticas y estrategias de internacionalización prioritarias en el conjunto del sistema universitario español se encuentran las siguientes acciones:

1. Intercambio de estudiantes, profesores y PAS como aspecto creciente de la internacionalización.

2. Desarrollo y contraste de los estándares académicos y de aseguramiento de la calidad.

3. Colaboración internacional en educación, investigación e innovación.

4. Internacionalización de las estructuras de gestión.

\section{OBJETIVOS Y METODOLOGÍA}

Teniendo en cuenta la importancia, el interés y los esfuerzos que en materia de internacionalización llevan a cabo las instituciones de educación superior en España, la presente investigación se centra en las acciones que en este campo ejecutan las cinco universidades públicas de la Comunitat Valenciana (Universitat de València, Universitat Politècnica de València, Universitat Jaume I, Universitat d'Alacant y Universidad Miguel Hernández de Elche) a través del análisis de las estrategias y 
los medios empleados, fundamentalmente el uso que le confieren a las TIC, tomando como referencia para el estudio los perfiles oficiales de estas cinco instituciones en Twitter ${ }^{1}$, una de las redes sociales con mayor número de usuarios en la actualidad y que, según García García (2018), es la plataforma más importante para las universidades españolas seguida de Facebook y LinkedIn. También Simancas-González y García-López (2017) señalan que los perfiles institucionales en redes sociales, sobre todo Facebook y Twitter, son el segundo medio más citado por responsables de comunicación de universidades españolas como principal canal de comunicación interna y externa tras la web institucional. En el desarrollo de este trabajo se han fijado los siguientes objetivos:

Objetivo general: Evaluar la importancia que las universidades públicas valencianas confieren a la internacionalización a través de su comunicación institucional mediante Twitter.

Objetivo específico 1: Medir qué factores de internacionalización resultan prioritarios en la comunicación universitaria a través de Twitter.

Objetivo específico 2: Observar las características formales dominantes en aquellos tuits dirigidos al fomento de la internacionalización universitaria (lengua empleada, elementos incorporados, enlaces, etiquetas, etc.).

Objetivo específico 3: Examinar la autoría de los tuits dirigidos a la internacionalización de la institución.

1 Tanto la Universitat Jaume I (UJI) como la Universitat d'Alacant (UA) cuentan con dos perfiles oficiales en Twitter, uno principalmente en castellano y el otro en valenciano. Para la presente investigación se optó por analizar en cada uno de los casos el perfil con mayor número de seguidores y ritmo de actualización, lo que supuso someter a examen el perfil en valenciano de la UJl y el perfil en castellano de la UA.
Objetivo específico 4: Analizar el feedback generado por aquellos tuits de la institución universitaria que persiguen fomentar la internacionalización.

Los datos analizados corresponden a los meses de junio, julio y septiembre de 2018, ya que estas son fechas clave en las estrategias de internacionalización universitaria, debido a que los dos primeros meses se corresponden con la etapa de finalización del período de estudios y el último con el inicio del programa regular. No se tuvo en cuenta el mes de agosto, dado que se trata de un período en el que la universidad española no se encuentra prestando servicios.

Para poder responder a los objetivos fijados, se llevó a cabo el análisis de un total de 1.581 publicaciones realizadas por dichas instituciones en el período señalado. Para su codificación de acuerdo con los factores de internacionalización, se siguieron los criterios recogidos en el epígrafe 4 del documento Estrategia para la internacionalización de las universidades españolas 2015-2020 elaborado por el Ministerio de Educación, Cultura y Deporte (2014)², diferenciando cuatro categorías:

- a) Movilidad de entrada y salida. Captación de talento.

La movilidad de estudiantes, investigadores jóvenes, profesores y personal de administración y servicios ha sido considerada como el motor de la internacionalización. Según los datos recogidos en la memoria ministerial, se espera que para finales de la década 2010-2020, la

2 Los factores 4.2 (Reconocimiento de periodos de estudio y de titulaciones), 4.3 (Acreditación del personal docente e investigador) y 4.4. (Acreditación de programas) recogidos en el documento ministerial no se han tenido en cuenta en el diseño del instrumento de codificación dado que se trata de acciones de carácter administrativo difícil de plasmar en comunicación 
cantidad de estudiantes móviles crezca hasta los 7 millones. Para el análisis de esta categoría se establecieron tres subniveles. El primero de ellos se corresponde con acciones dirigidas a la movilidad de estudiantes, teniendo en cuenta como movilidad de entrada todas aquellas publicaciones que promuevan programas de grado o maestrías de la universidad, así como cursos cortos de máximo 3 meses de duración; y de salida aquellas publicaciones que incentiven a los estudiantes y maestrantes a realizar estancias cortas o largas en otros centros de educación superior distintos a la institución generadora del mensaje. En la misma línea se concibe el segundo subnivel, aunque en este caso dirigido a la clasificación de acciones de movilidad que tengan como destinatarios al personal docente, investigadores y al personal de administración y servicios.

Como tercer subnivel se consideran aquellas publicaciones relacionadas con Investigación y Doctorado Internacional (factor 4.5 del documento ministerial), centrado en aquellos mensajes vinculados con el incentivo de programas de doctorado, en el desarrollo de medidas de movilidad internacional, ya sea hacia la universidad (entrada) como también los dirigidos a aquellos doctorandos que deseen realizar estancias cortas fuera de la institución (salida), con el apoyo de programas de movilidad tanto propios de las universidades, como nacionales o de la UE.

- b) Transferencia de conocimiento e innovación.

En correspondencia con el apartado 4.6 del documento del Ministerio referente a la Transferencia de Conocimiento e innovación, enfocada a potenciar el liderazgo internacional de las universidades españolas, esta categoría será aplicable a aquellas publicaciones que promuevan la transferencia de conocimientos y tecnologías entre los ámbitos académicos y empresarial, en entornos abiertos y flexibles de colaboración en I+D+i, incluyendo la interacción, difusión y adopción de modelos compartidos de nuevas ideas, además de la comercialización de los resultados I+D+i y del fortalecimiento de la actividad emprendedora nacida en la universidad.

Para el análisis de esta categoría se consideran dos subfactores. Por un lado, el de Relaciones Internacionales, vinculado con las referencias a convenios o entendimientos de colaboración entre universidades (nacionales o extranjeras) o con Centros I+D y Empresas. Cada una de estas subcategorías es mutuamente excluyente para su análisis estadístico. Por otro, el subfactor correspondiente a la Promoción de resultados, clasificándolos como propios (aquellas publicaciones que se refieran a resultados de investigaciones realizadas por personal de la universidad, ya sea en colaboración con personal de otras universidades o 100\% de la institución, además de eventos, congresos y talleres, logros alcanzados por el personal de la universidad: estudiantes, profesores o investigadores) o externos (aquellas publicaciones referentes a resultados de investigaciones ajenas a la institución pero que resultan interesantes o atractivos para las líneas de investigación desarrolladas por el personal interno o adjunto).

\section{- c) Empleabilidad}

Corresponde al factor 4.7 de la memoria ministerial, que se relaciona con la potencialidad para conseguir el primer empleo y adaptarse a los cambios que pueden producirse en el futuro. Esta categoría codificará aquellas publicaciones que fomenten el empleo, incluyendo aspectos de inserción laboral en los programas de la movilidad, además de aquellas que fomenten programas cooperativos internacionales con la industria y el sector empresarial, con el uso de diferentes mecanismos: cátedras de 
empresas, pasantías, estancias en empresas para profesores e investigadores, captación de profesores visitantes de la industria y formación de emprendedores internacionales; así como aquellas publicaciones que contengan ofertas de trabajo o hagan alusión a las mismas, clasificándolas en nacionales o exteriores.

- d) Cooperación en educación con otras regiones

Correspondiente al factor 4.8 recogido por el documento del Ministerio y relacionado con la cooperación en educación con otras regiones del mundo. Gran parte de la movilidad pasa por el conocimiento y la difusión de información acerca de las posibilidades que ofrece España y su sistema universitario. Esta categoría englobará a aquellas publicaciones que promuevan las universidades públicas objeto de estudio y que tengan por finalidad avanzar en los objetivos de difusión de la lengua y cultura españolas, incentivando con ello la demanda de estudios en español, ya que el conocimiento del idioma y el interés por la cultura española suelen ser algunas de las principales razones que mueven a los estudiantes a la hora de elegir España como destino en sus estudios. Son estos alumnos y alumnas quienes, junto con sus familias, se convierten posteriormente en difusores de la cultura española e impulsores de relaciones de todo tipo con España.

A partir de la revisión de estos cuatro factores de internacionalización, y de los objetivos señalados anteriormente, se diseñó una plantilla de codificación para realizar un análisis de contenido de tipo cuantitativo que permitiera extraer datos con los que poder contrastar la actividad en Twitter de las cinco instituciones objeto de estudio. La codificación de las unidades de análisis se llevó a cabo a partir de la consideración de cinco variables: correspondencia con políticas de internacionalización, factores de internacionalización presentes, características formales del tuit, autoría y feedback.

\section{DESCRIPCIÓN DE RESULTADOS}

\subsection{TUITS RELACIONADOS CON POLÍTICAS DE INTERNACIONALIZACIÓN}

De las 1.581 publicaciones analizadas, 628 se corresponden con tuits en los que se identifican estrategias ligadas a políticas de internacionalización, lo cual representa el 40\% del total de los mensajes analizados. Este valor fue superado en algunas de las universidades, siendo la Universitat Jaume I (UJ) la que muestra un mayor porcentaje de tuits vinculados a objetivos de internacionalización, observables en el $42 \%$ de sus publicaciones. En el extremo contrario, la Universitat de València (UV) reportó el menor porcentaje, con un 35\%, quedando ligeramente por debajo de la media global (Figura 1).

\subsection{FACTORES DE INTERNACIONALIZACIÓN DOMINANTES}

\subsubsection{MOVILIDAD DE ENTRADA Y SALIDA. CAPTACIÓN DE TALENTO}

Uno de los factores de internacionalización con gran importancia para las universidades es la movilidad del personal y la atracción hacia los campus de investigadores y estudiantes mediante mensajes como el que puede observarse en la Imagen 1. Este factor representa el $32 \%$ de las publicaciones enmarcadas en estrategias de internacionalización, con un total de 201 tuits (véase Figura 2), valor superado por la 


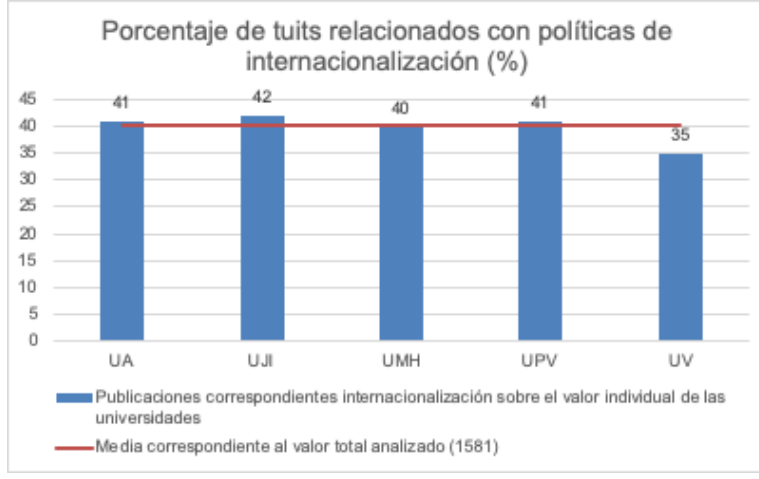

Figura 1. Valores correspondientes al total de publicaciones sobre internacionalización.

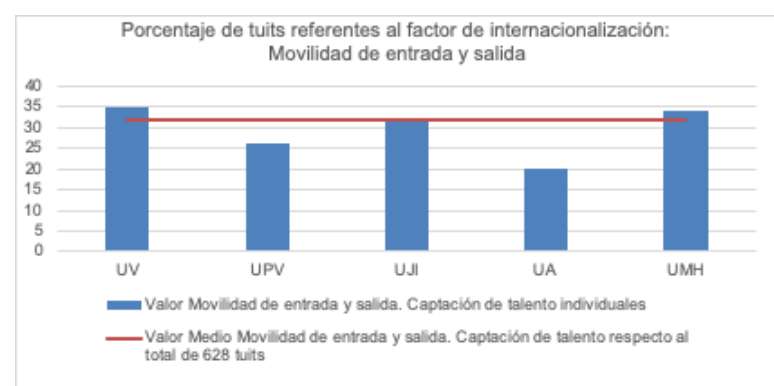

Figura 2. Valores correspondientes al total de publicaciones sobre el factor de Movilidad entrada y Salida. Captación de talento.

comunicación en Twitter de las universidades UV, UJl y Universidad Miguel Hernández de Elche $(\mathrm{UMH})$, quedando rezagadas en este sentido la Universitat Politècnica de València (UPV) y la Universitat d'Alacant (UA), esta última con un discreto 20\% (Figura 2 y 3 )

\subsubsection{TRANSFERENCIA DE CONOCIMIENTOS E INNNOVACIÓN}

En relación con los contenidos de sus perfiles en Twitter, podemos apreciar que las universidades valencianas en su conjunto otorgan gran importancia a la difusión de su actividad científica, concordando con la importancia otorgada a la innovación y la tendencia a la internacionalización del conjunto de universidades españolas (García García, 2018).
Universitan Valemtia OUN, EG - 25 sept 2018

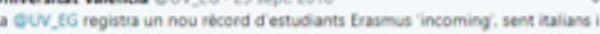

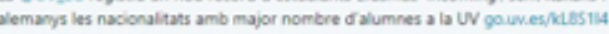
6 induce feret

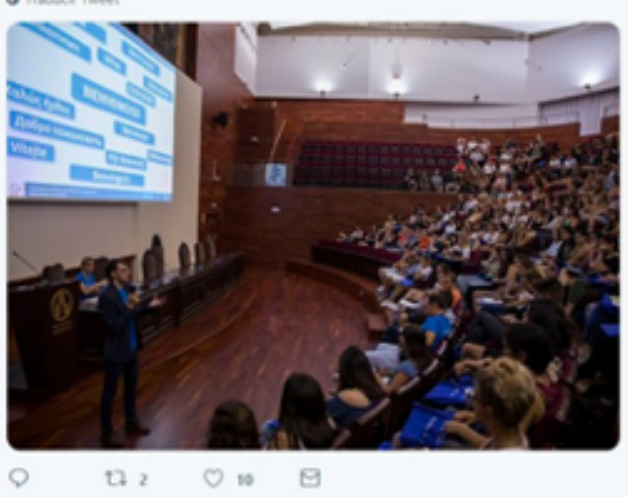

Figura 3. Ejemplo de publicación correspondiente con los Factores de Internacionalización. Movilidad de entrada y salida. Captación de talento (programa de grado en la UV)

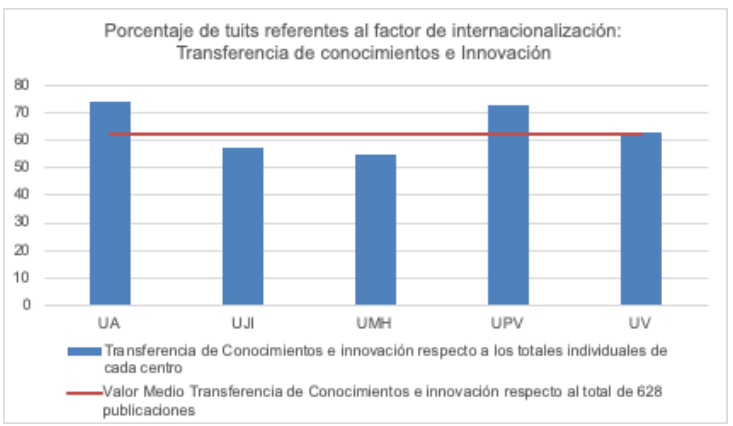

Figura 4. Ejemplo de publicación correspondiente al Factor de Internacionalización. Transferencia de conocimientos e innovación. (Promoción de resultados propios de la institución)

Universidad de Alicante UA OUA_Universidad - 6 jun

I. 25 UN MATERIAL AUTORREPARABLE CREADO POR LA NUA,

ROTAGONISTA HOY EN Pla2_tive, Il reportaje forma parte de la serie "Lo Universidad Responde" coordinada por @CrueUniversidad Disponible en

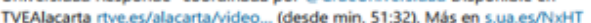

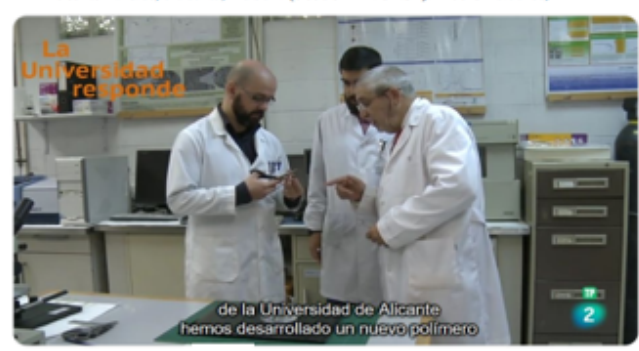

○

Figura 5. Ejemplo de publicación correspondiente al Factor de Internacionalización. Transferencia de conocimientos e innovación. (Promoción de resultados propios de la institución) 
En las universidades públicas valencianas la transferencia de conocimientos e innovación se encuentra reflejada en el $62 \%$ del total de 628 tuits vinculados a políticas de internacionalización. La hegemonía de este factor al ser observado en 391 publicaciones del corpus se encuentra en concordancia con la tendencia nacional, en la que la innovación emerge como asunto clave al tratarse de un claro punto de encuentro entre la universidad y la sociedad (García García, 2018). En este caso, no obstante, el comportamiento de cada universidad resultó variable. Tres de las instituciones analizadas reportaron valores por encima de la media global, destacando la Universitat d'Alacant (UA) con el $74 \%$ de sus publicaciones dedicadas a este apartado. Por otro lado, con un 57\% y 55\% respectivamente, las universidades UJI y UMH quedaron ligeramente por debajo de la media global. En el Gráfico 3 se muestra el comportamiento de este indicador por cada una de las instituciones analizadas respecto a la media general. En la Imagen 2 podemos observar un ejemplo de este tipo de publicación, en este caso corresponde a la promoción de resultados propios (Figura 4 y 5).

\subsubsection{EMPLEABILIDAD Y COOPERACIÓN EN EDUCACIÓN CON OTRAS REGIONES}

Los apartados de Empleabilidad y Cooperación en Educación con otras regiones representan valores casi nulos. De hecho, en conjunto suponen aproximadamente el $6 \%$ del total de publicaciones, con 35 tuits, motivo por el que se exponen de manera conjunta en este subapartado. La escasa presencia de estos factores en gran medida es debido a que los esfuerzos de las instituciones de educación superior pare- cen estar concentrados en la promoción de resultados de investigación y en el incentivo de atracción de talento hacia sus distintos centros universitarios como principales estrategias de internacionalización de sus campus. Individualmente, cada universidad maneja estos temas de forma muy diferente (ver Gráfico 4). Mientras en la UV (ver Imagen 3) estos valores representan el 2\% de tuits, la UJl les dedica el $11 \%$ de los mensajes enmarcados en estrategias de internacionalización publicados en su perfil en Twitter (Figura 6 y 7 ).

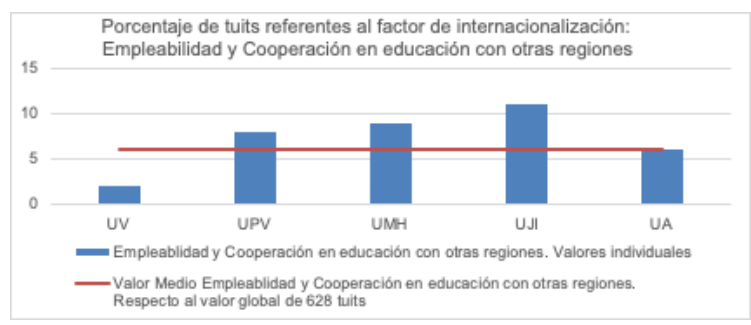

Figura 6. Comparación de los valores con respecto a los Factores de Empleabilidad y Cooperación en educación en otras regiones con la media global.

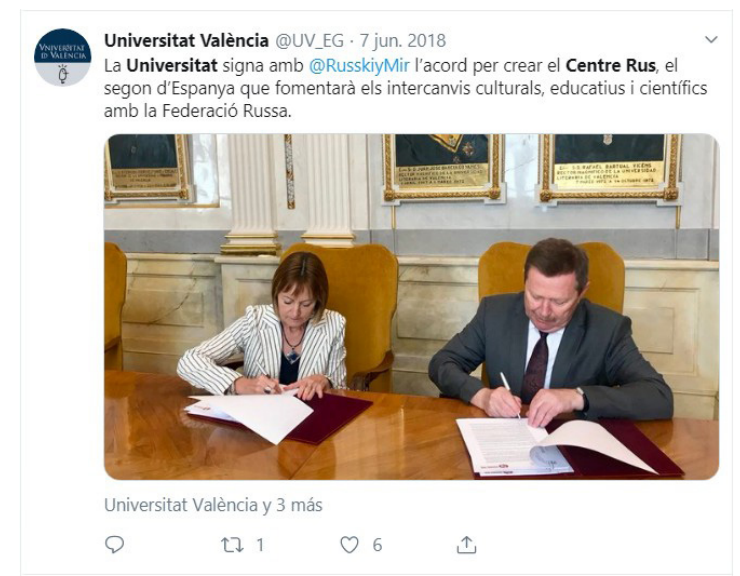

Figura 7. Publicación correspondiente a los Factores de Internacionalización. Empleabilidad y Cooperación en educación con otras regiones. 


\subsection{COMPOSICIÓN DE LOS TUITS SOBRE INTERNACIONALIZACIÓN: PRINCIPALES CARACTERÍSTICAS}

\subsubsection{USO DE IMÁGENES Y ELEMENTOS AUDIOVISUALES}

La composición de los tuits es homogénea en las universidades analizadas, con amplio uso de imágenes en combinación con textos, siendo muy deficiente el uso de videos, el cual no supera el $2 \%$ del total de las publicaciones. Las imágenes son, sin embargo, ampliamente empleadas, al encontrarse presentes en el $76 \%$ de tuits respecto al total de publicaciones relacionadas con factores de internacionalización. Analizando cada universidad por separado, podemos apreciar que la mayoría supera el umbral del 70\% en relación con el uso de las imágenes como componente de sus tuits, excepto la UPV, que solo las empleó en el 59\% de las ocasiones (ver Figura 9). En la Figura 8 puede observarse un ejemplo de esta combinación texto-imagen.

\subsubsection{USO DE ENLACES}

Una composición ampliamente empleada es la inclusión de enlaces en las publicaciones. Estos pueden redirigir a los usuarios hacia portales web de la institución y, en algunos casos, hacia otros sitios web con el fin de ampliar la información difundida en las publicaciones. En el $80 \%$ de las ocasiones fueron utilizados enlaces que apuntaban hacia el sitio web institucional, atrayendo tráfico hacia la universidad. Dos de las cinco universidades superaron esta media: la UJl y la UPV, con un 93\% y $87 \%$ respectivamente, siendo la UMH la que menor uso hizo de este recurso, presente solo en el 66\% de sus mensajes. En la Figura 10 se puede apre-

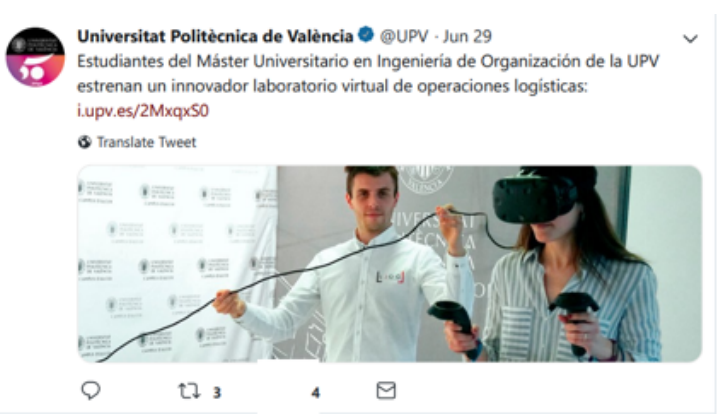

Figura 8. Publicación correspondiente a los Factores de Internacionalización. Empleabilidad y Cooperación en educación con otras regiones.

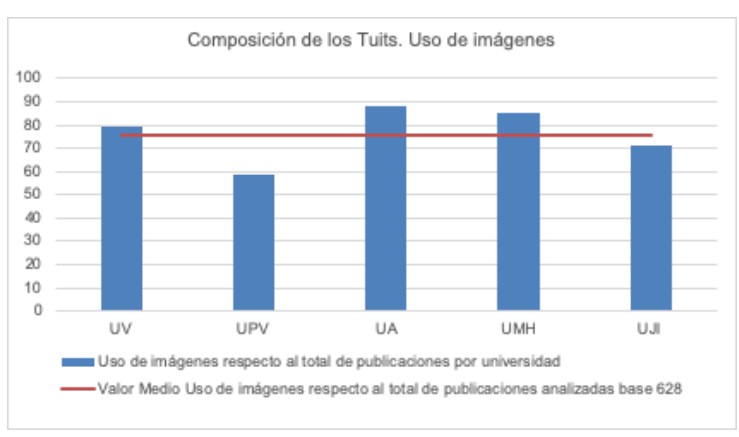

Figura 9. Composición de los tuits. Uso de imágenes en las publicaciones.

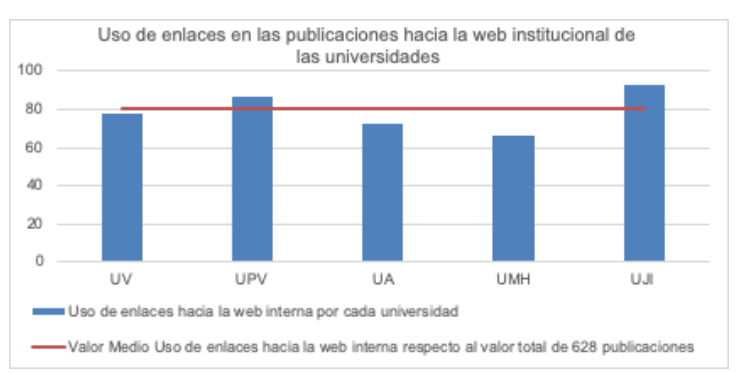

Figura 10. Comportamiento de los enlaces hacia la web institucional respecto a la media.

ciar mejor la diferencia de su uso entre las universidades. En la Imagen 4 puede observarse un ejemplo del uso de inclusión de enlaces hacia la web institucional en un tuit acompañado de imagen.

El resto de los porcentajes corresponden a enlaces hacia sitios de dominio nacional (.es), en el $6 \%$, mientras que en el $4 \%$ redirigen el tráfico web hacia otros dominios en Internet. El 10\% restante corresponde a publicaciones donde no se empleó ningún tipo de enlace. Esta úl- 
tima opción varió de una universidad a otra, siendo la UMH la que con mayor frecuencia publicó tuits que no incluyen enlace alguno.

\subsubsection{IDIOMA EMPLEADO}

Los seguidores con los que cuentan estos perfiles son diversos y de latitudes diferentes, siendo el idioma un factor muy importante en la comunicación. La composición general está dada por el uso alternativo del español y valenciano, aunque varias universidades optan por publicar en uno u otro idioma. Un ejemplo de ello es la UJI que posee dos perfiles en Twitter, uno con noticias escritas en más de un 95\% en valenciano y otro perfil en español. Ambos comparten noticias similares, pero el primero es el que mayor número de seguidores posee. Otro ejemplo es el de la UA que igualmente posee dos perfiles independientes en distintas lenguas, con noticias similares. De forma general se puede apreciar que, aunque el valenciano es ampliamente empleado en los perfiles oficiales de las universidades, siendo junto al castellano lengua cooficial de la Comunitat Valenciana, a nivel global el mayor porcentaje mensajes de las instituciones analizadas a través de Twitter se difunde en español (50\% de tuits), seguido del valenciano (presente en el $40 \%$ de las publicaciones enmarcadas en políticas de internacionalización) y, en menor medida, del inglés (presente en el $10 \%$ de los tuits que han sido codificados como mensajes alineados con estrategias de internacionalización).

Analizadas de manera individual, observamos cierta variación de los datos según la universidad. Las instituciones con mayor uso del valenciano sobre el español son la UV y UJl, con el $83 \%$ y $76 \%$ respectivamente; el resto de publicaciones están escritas en castellano. Por otro lado, los perfiles en Twitter de la UA (96\%), la UMH (93\%) y la UPV (80\%) son los que mayor uso del castellano evidencian en el conjunto de

\begin{tabular}{|c|c|c|c|}
\hline \multicolumn{3}{|c|}{$\begin{array}{c}\text { Espa- } \\
\text { ñol }\end{array}$} & $\begin{array}{c}\text { Va- } \\
\text { len- } \\
\text { ciano }\end{array}$ \\
$\begin{array}{c}\text { In- } \\
\text { glés }\end{array}$ \\
$\begin{array}{c}\text { Universitat } \\
\text { de València }\end{array}$ & $17 \%$ & $83 \%$ & $0 \%$ \\
\hline $\begin{array}{c}\text { Universitat } \\
\text { Politècnica de València }\end{array}$ & $80 \%$ & $23 \%$ & $0 \%$ \\
\hline $\begin{array}{c}\text { Universitat d'Alacant } \\
\text { Universidad Miguel } \\
\text { Hernández de Elche }\end{array}$ & $96 \%$ & $3 \%$ & $1 \%$ \\
\hline Universitat Jaume I & $24 \%$ & $76 \%$ & $0 \%$ \\
\hline
\end{tabular}

Tabla 1. Uso de idioma español, valenciano e inglés en las publicaciones realizadas por las universidades respecto a los factores de informatización.

sus publicaciones. Las dos primeras emplearon, además, el inglés de forma puntual en sus tuits, con el $1 \%$ y $2 \%$ respectivamente. En la tabla siguiente se muestra esta relación: (Tabla 1).

\subsubsection{USO DE ETIQUETAS}

Uno de los conceptos más populares, por su uso extensivo tanto en perfiles personales como institucionales, son los hashtags, los cuales permiten clasificar y categorizar la temática de los mensajes que son publicados en las redes sociales, en especial Twitter (Castelló Martínez, 2013). Aun así, su uso por parte de las universidades de la Comunitat Valenciana es reducido. De forma general fueron empleados en el $43 \%$ de las 628 publicaciones analizadas, aunque este valor varía respecto a las instituciones analizadas; la UA (ver Imagen 5) y UMH son las únicas que superan ese valor, con $68 \%$ y $76 \%$ respectivamente, el resto no alcanza el 40\%: la UJl hizo uso de etiquetas en el 38\%, seguido con un $20 \%$ por la UV y la que menos valores reportó fue la UPV, con un 8\% (Figura 11 y 12$)$ 


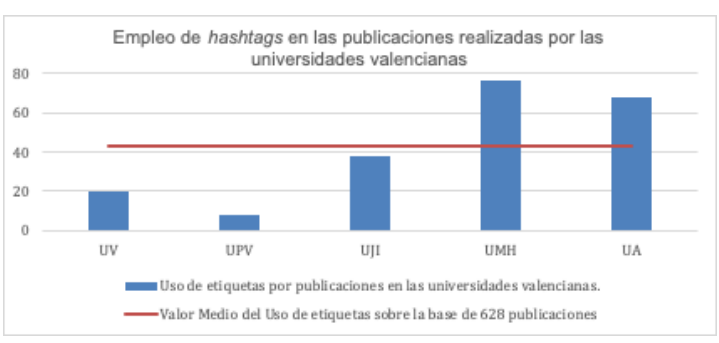

Figura 11. Uso de etiquetas en las publicaciones sobre internacionalización de las universidades valencianas.

Universidad de Alicante UA EUA Universidad - 11 jun.

UNO DE LOS NUESTROS, A SILLCON VALLEY

Enhorabuena! nuestro companero Alvaro Belmonte, alumno de

IIngenieriatrobótica en la aUA, es uno de los 4 españoles elegidos para participar en Imagine Silicon Valley 2018 Más info bitly/2LEpkl2 mtalentol syocreotalento

Figura 12. Uso de hashtags en las publicaciones correspondientes a los Factores de Internacionalización.

\subsection{AUTORÍA DE LOS TUITS RELACIONADOS CON INTERNACIONALIZACIÓN}

Los tuits que quedaron enmarcados en publicaciones relacionadas con factores de internacionalización fueron clasificados en originales, generados por la propia institución universitaria que los difunde o retuits. La mayoría de las publicaciones (93\%) de los 628 tuits analizados quedaron categorizados como originales. Esta hegemonía es similar en cada una de las universidades analizadas: cuatro universidades muestran valores iguales o superiores al 90\%, mientras que solo la $\mathrm{UMH}$ posee un valor inferior, situado en el $81 \%$, tal y como se muestra en la Figura 13.

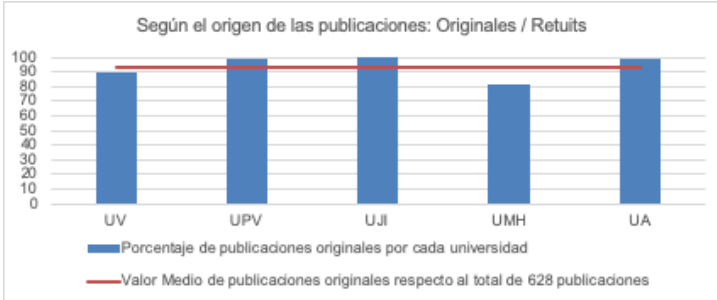

Figura 13. Autoría original de los tuits analizados

\subsection{FEEDBACK EN TUITS RELACIONADOS CON POLIITICAS DE INTERNACIONALIZACIÓN}

En relación con las interacciones registradas en las publicaciones sobre políticas de internacionalización, todas las universidades lograron algún tipo de reacción en los tuits enmarcados en esa categoría, ya sea por me gusta, comentarios o retuits. La cantidad de interacciones de un tipo $u$ otro dependen en gran medida de los recursos multimedia empleados, como revela el cruzar los datos obtenidos en la codificación de la presencia de imágenes y elementos audiovisuales con los registrados con relación a la respuesta de los usuarios de Twitter. De este modo, aquellas publicaciones que incluían imágenes en sus publicaciones obtuvieron un mayor feedback que aquellas que solo contenían textos. Como promedio general por cada publicación se obtuvieron 13 likes, 0.2 comentarios y 6 retuits; en la tabla siguiente se muestra por cada universidad el promedio de interacción que recibieron por cada publicación realizada (Tabla 2).

\begin{tabular}{|c|c|c|c|}
\hline Universidad & \multicolumn{1}{c}{$\begin{array}{c}\text { Me } \\
\text { Gusta }\end{array}$} & $\begin{array}{c}\text { Comen- } \\
\text { tarios }\end{array}$ & Retuits \\
\hline $\begin{array}{c}\text { Universitat de } \\
\text { València }\end{array}$ & 13 & 0.2 & 6 \\
\hline $\begin{array}{c}\text { Universitat } \\
\text { Politècnica de } \\
\text { València }\end{array}$ & 13 & 0.2 & 7 \\
\hline $\begin{array}{c}\text { Universidad } \\
\text { Miguel Hernández } \\
\text { de Elche }\end{array}$ & 10 & 0.2 & 6 \\
\hline $\begin{array}{c}\text { Universitat Jau- } \\
\text { me I }\end{array}$ & 4 & 0.06 & 2 \\
\hline $\begin{array}{c}\text { Universitat } \\
\text { d'Alacant }\end{array}$ & 14 & 0.4 & 8 \\
\hline
\end{tabular}

Tabla 2. Promedio de interacciones recibidos por cada publicación relacionada con la internacionalización. 


\section{CONCLUSIONES}

Tras el estudio y análisis de los tuits que conforman el corpus, puede afirmarse que las universidades públicas de la Comunitat Valenciana otorgan gran importancia a la proyección de sus políticas de internacionalización, en la dirección que apuntan las estrategias diseñadas por el Ministerio, según queda avalado por los esfuerzos que se observan a través de su comunicación institucional por medio de sus perfiles en Twitter.

Este énfasis en las políticas de internacionalización se sitúa en el marco de la estrategia definida por el Ministerio de Educación, Cultura y Deporte de España en 2014 para el periodo 2015-2020, destacando la comunicación de las acciones relacionadas con la innovación y la transferencia de conocimientos, prioridad de las universidades públicas valencianas, lo que sitúa esta apuesta como uno de los pilares básicos de la actividad comunicativa universitaria, como punto de encuentro entre universidad y sociedad, al tener la capacidad de situar a estas instituciones en la esfera internacional como centros dinámicos y atractivos. En segundo lugar, las instituciones examinadas también evidencian un elevado interés por potenciar las acciones de Movilidad de entrada y salida - Captación de talento. En conjunto, ambos factores representan el 93\% de todas las publicaciones analizadas.

Como hemos apreciado, para la difusión de las políticas de internacionalización a través de Twitter, las universidades públicas valencianas otorgan un mayor peso al uso de imágenes fijas sobre otros recursos multimedia, como los vídeos, para proyectar estas estrategias. Además, en la mayor parte de ocasiones, los tuis examinados se enriquecen a partir de la inclusión de enlaces que dirigen a los seguidores hacia webs, prioritariamente de carácter institu- cional, para ampliar las informaciones; en otras ocasiones son dirigidos hacia sitios de interés nacionales, pero son los menos. De este modo, se comprueba que la comunicación institucional en Twitter de las universidades públicas valencianas relacionada con políticas de internacionalización se encuentra en concordancia con las tendencias observadas a nivel nacional, que priorizan los contenidos relacionados con la marca en formato imagen o link seguido del formato video (García García, 2018). La misma voluntad de incrementar la proyección internacional de la institución podría explicar que, en general, las universidades privilegien el español frente al valenciano, lengua cooficial en la Comunitat Valenciana, que solo domina en el caso de la Universitat de València y de la Universitat Jaume I. La apuesta por las políticas de internacionalización no contribuye, sin embargo, a introducir de forma significativa la lengua inglesa en la comunicación corporativa de estas universidades, en cuyos mensajes es prácticamente inexistente.

La Educación Superior puede y debe adaptarse a los nuevos requerimientos de la sociedad y contribuir a superar posiciones de desigualdad frente a los procesos de globalización, abordando las relaciones interuniversitarias y entre universidad-sociedad desde la lógica de la cooperación y no de la competitividad. El factor de internacionalización ligado a objetivos cooperativos debiera ocupar un lugar más destacado tanto en la misión como en la comunicación institucional de las universidades contemporáneas. En el siglo XXI, la Educación Superior ha sido reconocida como factor de desarrollo de las naciones (Sacasas-López, 2014), un propósito para el que resulta de vital importancia no solo el desarrollo de políticas y estrategias de internacionalización sino también su adecuada comunicación, pues muchas de ellas solo pueden ejecutarse con éxito mediante el con- 
curso de actores individuales e institucionales cuya contribución es indispensable. Por ello, el uso responsable y eficaz de las TIC como herramientas fundamentales para cumplir los objetivos de internacionalización trazados por cada institución, en el marco de las estrategias nacionales, aporta también progreso al país, al reconocerse a las universidades como artífices del desarrollo científico-tecnológico de nuestros tiempos.

\section{REFERENCIAS BIBLIOGRÁFICAS}

Baelo, R. \& Cantón, I. (2010). Las tecnologías de la comunicación en las Universidades de Castilla y León. Comunicar, 35(XVIII), 159-166. doi: 10.3916/C35-2010-03-09

Castelló Martínez, A. (2013). El uso de hashtags en Twitter por parte de los programas de televisión españoles. Actas del I Congreso Internacional de Comunicación y Sociedad. Logroño: UNIR. Recuperado de: https://rua.ua.es/dspace/bitstream/10045/67420/1/2013_Araceli-Castello_Congreso-Comunicacion-y-Sociedad-1.pdf [Consultado el 11/01/2019]

García García, M. (2018). Universidad y medios sociales: Gestión de la Comunicación en la Universidad Española. Revista Prisma Social, 22, 20-36.

Gómez, M., Roses, S. \& Farias, P. (2012). El uso académico de las redes sociales en universitarios. Comunicar, 38(XIX), 131-138. doi: 10.3916/ c38-2012-03-04 
González-Díaz, C., Iglesias-García, M. \& Codina LII. (2015). Presencia de las universidades españolas en las redes sociales digitales científicas: caso de los estudios de comunicación. El profesional de la información, 24(5), 640-647. doi: 10.3145/epi.2015.sep.12

Macías-Alegre, A. (2016). El Crossumer, la evolución del consumidor mediada por las tecnologías sociales y la hiperconectividad móvil. Métodos de Información, 7(12), 5-16.

MECD (2014). Estrategia para la internacionalización de las universidades españolas 2015-2020. Recuperado de: http://www.educacionyfp.gob. es/educacion-mecd/dms/mecd/educacion-mecd/areas-educacion/ universidades/politica-internacional/estrategia-internacionalizacion/ Estrategialnternacionalizaci-n-Final.pdf [Consultado el 09/01/2019]

Moya Camacho, V. \& Orozco Ramírez, D.A. (2017). La influencia del marketing digital en los millenials mexicanos para fomentar el consumismo de moda rápida. Tesina. Universidad de Guadalajara. México.

Rama, C. (2012). La reforma de la virtualización de la universidad. El nacimiento de la educación digital. Guadalajara (México): UDG Virtual.

Reina Estevez, J., Fernández Castillo, I. \& Noguer Jiménez, Á. (2012). El Uso de las Redes Sociales en las Universidades Andaluzas: El Caso de Facebook y Twitter. Revista Internacional de Relaciones Públicas, 2(4), 123-144. doi: 10.5783/RIRP-4-2012-06-123-144

Sacasas-López, M. (2014). Estudio de modelos de control de gestión para la internacionalización universitaria en Cuba. Ingeniería Industrial, 35(3), 312-321.

Sangrà, A. \& González Sanmamed, M. (Coord.) (2004). La transformación de las universidades a través de las TIC: discursos y prácticas. Barcelona: Editorial UOC.

Simancas-González, E., \& García-López, M. (2017). Gestión de la comunicación en las universidades públicas españolas. El profesional de la información, 26(4), 735-744. doi: 10.3145/epi.2017.jul.17

Takaki, M., Bravo, R., \& Martínez, E. (2015). La gestión de la identidad corporativa en la Universidad: análisis y consecuencias desde la perspectiva del profesorado. Revista Europea de Dirección y Economía de la Empresa, 24, 25-34. doi: 10.1016/j.redee.2014.05.001 